\title{
CHANGES IN PHYSICAL FITNESS OF HUNGARIAN COLLEGE STUDENTS IN THE LAST FIFTEEN YEARS
}

\author{
MónIKA KaJ, ${ }^{1}$ Éva TÉKus, ${ }^{1,2}$ IVETT JuhÁsz, ${ }^{3}$ \\ KaTINKA STOMP 3 and MÁrta WiLHELM ${ }^{3 *}$ \\ ${ }^{1}$ Doctoral School of Health Sciences, University of Pécs, Pécs, Hungary \\ ${ }^{2}$ Department of Sportbiology, University of Pécs, Ifjúság útja 6, H-7624 Pécs, Hungary \\ ${ }^{3}$ Department of Leisure Sports and Recreation, University of Pécs, \\ Ifjúság útja 6, H-7624 Pécs, Hungary
}

(Received: July 2, 2014; accepted: February 23, 2015)

\begin{abstract}
This study compared the physical fitness of Hungarian undergraduate students in 2011-2012 with the representative sample surveyed in 1997-1998. A total of 123 males and 309 females (mean age $21.19 \pm 2.19$ yrs) were randomly selected in two Hungarian universities (Pécs, Kaposvár). Anthropometric data (height, weight, skinfolds, body fat percentages) were measured and the subjects performed 9 tests of the Eurofit Fitness Test Battery. The BMI, total body fat and performance in most of the fitness components (balance, agility/speed, flexibility, abdominal muscular strength, aerobic fitness of females) was higher in 1997-1998 $(\mathrm{p}<0.05)$ whereas the handgrip strength and performance in Bent Arm Hanging test were significantly better in 2011-2012 ( $\mathrm{p}<0.001)$. These findings support interventions focusing on increasing regular physical activity among Hungarian youth.
\end{abstract}

Keywords: Young adults - anthropometry - physical fitness - Eurofit

\section{INTRODUCTION}

Many studies investigated the physical activity (PA), somatic status and lifestyle of the young, both in Hungary and elsewhere in the developed world [e.g. 4, 9, 16], the trend is negative $[7,8]$. Compared to earlier results young adults generally seem to perform worse [19, 36]. In 2000 the expected average lifetime spent in good health without any chronic diseases in Hungary was 62 and 58 years for the eighteen years old women and men, respectively. These expected lifetimes were 10-12 years shorter than for the 65 years old population. Every fifth person in Hungary is overweight or obese [31]. At the same time, many adults suffer from chronic cardiovascular and/or musculoskeletal diseases and from obesity in young age already $[31,46]$. The adiposity in adulthood can often be traced back to overweight in childhood and adolescence [35]. Low cardiorespiratory fitness is an important predictor of mortality caused by cardiovascular diseases and all-cause mortality especially in overweight or obese patients [45]. Most of these diseases could be prevented with lifestyle modifications

\footnotetext{
*Corresponding author; e-mail address: mwilhelm@gamma.ttk.pte.hu
} 
$[11,26]$, such as increasing PA and promoting dietary changes in overweight children and this could positively modify the components of metabolic syndrome [1].

An European representative survey has shown that in 2010, 77\% of the Hungarian population was inactive or did exercise less than once a week [13]. The realization of this problem has created support for new health-education programs and introduced positive examples for adolescents to contribute to the development of healthy adult lifestyle [17].

A large scale study was carried out in Hungary in 1997-1998 among 8100 college/ university students who were randomly selected in higher education institutions (HEI), representative of gender, age and geographic regions. The results showed that the health and fitness status of intellectuals were similar to the age-matched young adults of the developed Western-European countries [15]. Since then no similar representative study was conducted in Hungary although many changes have been introduced in the Hungarian education system. A decentralized curriculum introduced in 1995 provided great flexibility of curricular and pedagogical alternatives in the public education system. As a result, the time spent sitting in the classroom has increased while the hours of physical education (PE) decreased [18]. The number of PE sessions in HEI have decreased in the last few years as well [25]. On the other hand, alcohol drinking and smoking among students continuously increase during college and university years paralleled with irregular eating habits [2, 24]. A longitudinal study in the USA between 1996-2008 showed that PA and maximal oxygen uptake of university students were reduced along with an increase of bodyfat percentages [33]. Furthermore, even among medical students, the prevalence of overweight and low fitness does not differ from the other students or the average Hungarian young adult population [22]. In Canada, there was a dramatic increase in BMI from 1981 to 2009; also waist to hip ratio changed among children, youth and various adult groups in both sexes [3,42], paralelled with a significant decrease in flexibility and muscular strength [37]. A decreasing aerobic fitness in children and adolescents were also demonstrated worldwide, as a consequence of detraining and reduced PA [40].

Based on the above-mentioned findings the aim of this study was (i) to test the health-related fitness of Hungarian undergraduate students and (ii) to compare that with previous data set of the nation-wide research carried out in 1997 by the Hungarian Federation of University and Sport (MEFS) [15].

\section{MATERIALS AND METHODS}

\section{Participants}

Data were collected from a nationwide representative study organized by MEFS (participants were randomly selected attending to higher education in $1997, \mathrm{~N}=8100$; mean age $=20.97 \pm 5.04$ years, $56.3 \%$ girls (S1) [15], inclusion criteria met for a representative study. Many of the participants were reported as physically active. Results of S1 were compared to a cross-sectional study of volunteers in 2012 (S2) 
$(\mathrm{N}=432$, mean age $=21.2 \pm 2.19$ years, $71.5 \%$ girls $)$. The high percentage of females represented the ratio of sexes in these PE classes. Subjects in S2 are from two universities in Southern Hungary (Pécs, Kaposvár). All of the measured students participated in PA classes, once a week $(90 \mathrm{~min})$, offered at their universities. At these universities one PE course is compulsory (required in the curricula of any BA or BSc study), which can be accomplished in any of the first 4 Semesters. Participants were randomly selected from these classes, most of them were mildly active, very few participated in regular organized sport activities in sport clubs, but also very few had sedentary lifestyle. S1 is somewhat older, since the entire university student population (from 1-5 years) was measured, while in S2 mostly freshmen and sophomores were found. Exclusion criteria were set as follows: pregnancy, any muscoloskeletal diseases, infections, recent operation or trauma.

\section{Measurements}

The physical fitness of participants, including body composition, cardiopulmonary fitness, motor and musculoskeletal system fitness was evaluated in both sample using the Eurofit Fitness Test Battery [14].

\section{Anthropometric parameters}

To assess body composition, height was measured to the nearest millimeter with a certified stadiometer, and weight was measured with electronic scales (Omron model $\mathrm{SC} 100)$ to the nearest $0.1 \mathrm{~kg}$. From these we calculated the Body Mass Index $\left(B M I=\mathrm{kg} / \mathrm{m}^{2}\right)$ referring to the nutritional status of subjects. The cut off points for BMI are computed according WHO recommendations [46]. Lange Caliper was used for biceps, triceps, subscapular and suprailiaca skinfolds thickness measurements (in $\mathrm{mm}$ ) and the measurements were applied on the dominant side of the body. The measurements were carried out by the same trained personell. The percentage of body-fat was computed from four skinfolds according to Durnin and Womersley's [12] methods.

\section{Physical fitness}

All participants performed the Eurofit test battery, using the techniques described in the Eurofit handbook [14]. The reliability of using the Eurofit Fitness Test Battery by university students (test-retest) was proven by Tsigilis and collegues [44]. 


\section{Flamingo test}

This whole body balance test assesses the strength of the leg, pelvic and trunk muscles as well as dynamic balance. The subject stands on a specified beam bear foot and keeps balance on the preferred leg. The free leg is flexed at the knee and the heel of this leg is held close to the buttocks. The total number of step downs or balance losses in 60 seconds was recorded.

\section{Plate Tapping}

This test measures the speed and the coordination of limb movement. The subject moves the preferred hand back and forth between two discs on the table over the other hand in the middle as quickly as possible. The time taken to complete 25 cycles is recorded (the best result from two repetitions).

\section{Sit and Reach test}

This test measures the flexibility of the lower back and the hamstring muscles. The goal of the test is to reach with the hands as far as possible, while the subject is in sitting position on the floor with straight legs. The starting point of the scale was at $15 \mathrm{~cm}$. The score is registered to the nearest centimeter reached by the hand.

\section{Standing Long Jump}

The test measures the explosive power of lower limbs. The objective is to jump as far as possible. The distance is measured from the take-off line to the nearest point of contact with the ground. The best of three attempts was recorded in $1 \mathrm{~cm}$ accuracy.

\section{Handgrip Strength test}

This test measures the maximum isometric strength of the hand and forearm muscles. JAMAR Hydraulic Hand Dynamometer (Lafayette Instrument Company, USA) was used for the measurements. The test-retest reproducibility has evidence for good to excellent $(r>0.80)$ and excellent $(r=0.98)$ interrater reliability [32].

\section{Sit-Ups in 30 seconds}

The test measures the trunk (core) strength and abdominal muscular endurance. The contestant is to complete as many sit-ups as possible in 30 seconds. 


\section{Bent Arm Hang test}

The test measures the relative strength and endurance of the upper body. The subject is attempted to hold a lifting/hanging position on a bar for as long as possible. The total time is recorded in seconds.

\section{$10 \times 5$ meters Shuttle Run test}

This test measures the running speed and agility. The participant is to run between markers placed 5 meters apart, repeated ten times without stopping (covering 50 meters total). At each marker both feet must cross the line. The total time(s) taken to complete the $50 \mathrm{~m}$ course is registered.

\section{Maximal oxygen-uptake}

The maximal oxygen-uptake $(\mathrm{ml} / \mathrm{kg} / \mathrm{min})$ was predicted from the 20 meters Shuttle Run test using the following formula [30]:

$$
\mathrm{VO}_{2 \max }=40.35+0.21+(\text { laps })+4.27 *(\text { gender })+0.79 *(\text { age })-0.79 *(\mathrm{BMI})
$$

where gender $=1$ for male and 0 for female,

$\mathrm{VO}_{2 \max }$ : maximal oxygen uptake (relative $\mathrm{VO}_{2 \max }$ ),

age: decimal age,

laps: the number of laps completed in the $20 \mathrm{~m}$ Shuttle Run test,

BMI: Body Mass Index.

\section{Procedures}

The study was approved by the ethics committee of the University of Pécs and all participants gave their consent to participate. Informed consent form of University of Pécs, Institute of Sport Sciences and Physical Education was used for this protocol. The selection of the sample was randomized (University of Pécs and University of Kaposvár), meaning that courses and subjects were chosen randomly by PE teachers of the participating universities.

Data was collected in the academic year 2011-2012. All the measurments were taken by the same qualified and experienced personnel in Pécs and Kaposvár (Hungary) in the afternoon between 2 and 4 o'clock. The execution of the tests took place in the same order for all particiapants. Volunteers of S2 were students not involved in professional sport or PE degrees, the average time spent with physical 
activity is equal in both university's sample. The sample of S1 is a representative population of higher education, less than $1 \%$ of the studied population is involved in PE degrees.

\section{Analyses}

All data analyses was performed with IBM SPSS (version 19.0) statistical program. Descriptive statistics (mean, standard deviation) within the two sample groups were used to describe the main features of all measured data by sexes. Chi-square test was used to determine the differences in body composition categories between the sample from 1997-1998 (S1) and 2011-2012 (S2). The differences of physical fitness components were analyzed with Mann-Whitney U test, because data obtained in 19971998 were not homogenic and not normally distributed. Differences in the performance of S2 compared to S1 was calculated in percentages and standardized values were used to interpret the results on radar chart. P values are less than 0.05 on twoway tests were considered statistically significant ( $95 \%$ confidence interval).

\section{RESULTS}

Summary of anthropometric parameters of participants and the results of the Eurofit test battery is given in Table 1. Comparing S2 to S1, a significant difference was found in height (males: $U=125819.5, p=0.036$; females: $U=507614.5, p=0.001$ ), weight (males: $U=124289.5, p=0.011$; females: $U=456556.5, p<0.001$ ), BMI (males: $\mathrm{U}=125389, \mathrm{p}<0.037$; females: $\mathrm{U}=482487, \mathrm{p}<0.001$ ) and body fat percentages (males: $\mathrm{U}=55546, \mathrm{p}<0.001$; females: $\mathrm{U}=305352$; $\mathrm{p}<0.001$ ) in both sexes. The distributions of the BMI categories differ significantly in both sexes (M: $\left.\chi^{2}=37.901, \mathrm{df}=3, \mathrm{p}<0.001 ; \mathrm{F}: \chi^{2}=50.465, \mathrm{df}=3, \mathrm{p}<0.001\right)$ between the two samples; $70.8 \%$ of S1 and $60.7 \%$ of S2 belong to the normal nutritional status in males and $55 \%$ of S1 and $57.2 \%$ of S2 of females. According to BMI categories the ratio of underweight (13.9\% vs. $11.9 \%)$, overweight (13.7\% vs. $16.7 \%)$ and obese $(1.7 \%$ vs. $10.7 \%$ ) of males are in S1 and in S2, respectively. Among females the same values are $39.8 \%$ vs. $28 \%$ (underweight), $4.4 \%$ vs. $11.3 \%$ (overweight), and $0.9 \%$ vs. $3.5 \%$ (obese).

Figure 1 presents the standardized differences in physical fitness components between S1 and S2. Both sexes in S2 show significantly worse results in Flamingo test (males: $U=137665.5, p<0.001$; females: $U=336189, p<0.001$ ), Plate Tapping test (males: $U=110918, p<0.001$; females: $U=389063.5, p<0.001$ ), Sit and Reach test (males: $U=93349.5, p<0.001$; females: $U=316948.5, p<0.001$ ), Sit-Up test (males: $\mathrm{U}=134688.5, \mathrm{p}<0.001$; females: $\mathrm{U}=374559.5, \mathrm{p}<0.001$ ), and females in the $10 \times 5 \mathrm{~m}$ and $20 \mathrm{~m}$ Shuttle Run test $(\mathrm{U}=211392, \mathrm{p}<0.001)$. However, the results of the Handgrip Strength (males: $U=121282.5$, $p<0.001$; females: $U=329645$, $\mathrm{p}<0.001$ ) and Bent Arm Hanging test (males: $U=137952, p<0.001$; females: $\mathrm{U}=508434.5, \mathrm{p}<0.001)$ are significantly better in $\mathrm{S} 2$ than in $\mathrm{S} 1$ in both sexes. 
Table 1

Changes in anthropometric parameters and results of the Eurofit Fitness Test Battery between 1997-1998 and 2011-2012 differed by sex

\begin{tabular}{|c|c|c|c|c|c|c|c|}
\hline & \multicolumn{2}{|c|}{$1997-1998$} & \multicolumn{2}{|c|}{$2011-2012$} & \multirow{2}{*}{$\mathrm{U}$} & \multirow{2}{*}{ Sig. } \\
\hline & & Mean & SD & Mean & SD & & \\
\hline \multirow{2}{*}{ Height (cm) } & Males & 179.44 & 8.78 & 181.21 & 6.41 & 125820 & .036 \\
\hline & Females & 166.28 & 8.50 & 168.11 & 6.86 & 507615 & .001 \\
\hline \multirow{2}{*}{ Weight (kg) } & Males & 73.01 & 10.11 & 78.27 & 16.02 & 124290 & .011 \\
\hline & Females & 57.94 & 7.93 & 62.14 & 12.18 & 456557 & .000 \\
\hline \multirow{2}{*}{ BMI $\left(\mathrm{kg} / \mathrm{m}^{2}\right)$} & Males & 22.60 & 2.67 & 23.88 & 4.34 & 125389 & .037 \\
\hline & Females & 20.89 & 2.47 & 21.92 & 3.90 & 482488 & .000 \\
\hline \multirow{2}{*}{$\begin{array}{l}\text { Body fat percentages } \\
(\%)\end{array}$} & Males & 15.37 & 5.84 & 19.31 & 5.03 & 55546 & .000 \\
\hline & Females & 26.22 & 5.77 & 30.06 & 5.75 & 305352 & .000 \\
\hline \multirow{2}{*}{$\begin{array}{l}\text { Flamingo (number of } \\
\text { failures) }\end{array}$} & Males & 5.03 & 4.17 & 7.91 & 6.05 & 137666 & .000 \\
\hline & Females & 4.03 & 3.97 & 8.47 & 6.29 & 336190 & .000 \\
\hline \multirow{2}{*}{ Plate Tapping (sec) } & Males & 9.96 & 1.86 & 11.12 & 1.53 & 110918 & .000 \\
\hline & Females & 10.97 & 2.21 & 12.28 & 1.93 & 389064 & .000 \\
\hline \multirow{2}{*}{ Sit and Reach $(\mathrm{cm})$} & Males & 26.44 & 9.92 & 16.16 & 8.94 & 93350 & .000 \\
\hline & Females & 28.84 & 8.55 & 20.08 & 8.81 & 316949 & .000 \\
\hline \multirow{2}{*}{$\begin{array}{l}\text { Standing Broad Jump } \\
(\mathrm{cm})\end{array}$} & Males & 225.68 & 25.33 & 219.90 & 31.47 & 177840 & .179 \\
\hline & Females & 177.41 & 22.32 & 176.85 & 34.15 & 588437 & .011 \\
\hline \multirow{2}{*}{$\begin{array}{l}\text { Handgrip Strength } \\
(\mathrm{kg})\end{array}$} & Males & 45.70 & 10.83 & 52.99 & 12.01 & 121283 & .000 \\
\hline & Females & 26.89 & 9.84 & 34.58 & 11.60 & 329645 & .000 \\
\hline \multirow{2}{*}{ Sit-Up } & Males & 26.34 & 5.39 & 23.93 & 4.27 & 134689 & .000 \\
\hline & Females & 22.51 & 5.05 & 19.01 & 4.06 & 374560 & .000 \\
\hline \multirow{2}{*}{$\begin{array}{l}\text { Bent Arm Hanging } \\
\text { test (s) }\end{array}$} & Males & 37.50 & 18.22 & 45.33 & 21.50 & 137952 & .000 \\
\hline & Females & 17.75 & 17.25 & 23.75 & 19.67 & 508435 & .000 \\
\hline \multirow{2}{*}{$\begin{array}{l}10 \times 5 \mathrm{~m} \text { Shuttle Run } \\
\text { test }(\mathrm{s})\end{array}$} & Males & 19.50 & 2.11 & 19.55 & 2.16 & 175267 & .844 \\
\hline & Females & 21.37 & 2.32 & 21.81 & 2.62 & 405942 & .000 \\
\hline \multirow{2}{*}{$\begin{array}{l}20 \text { m Shuttle Run test } \\
\text { (number of shuttles) }\end{array}$} & Males & 55.02 & 36.72 & 60.20 & 25.77 & 211392 & .367 \\
\hline & Females & 39.87 & 22.66 & 35.58 & 16.16 & 211392 & .033 \\
\hline \multirow{2}{*}{$\begin{array}{l}\text { Maximal oxygen } \\
\text { uptake }(\mathrm{ml} / \mathrm{kg} / \mathrm{min})\end{array}$} & Males & 41.52 & 13.59 & 43.34 & 9.53 & 109772 & .467 \\
\hline & Females & 36.17 & 10.70 & 35.30 & 5.88 & 209195 & .073 \\
\hline
\end{tabular}




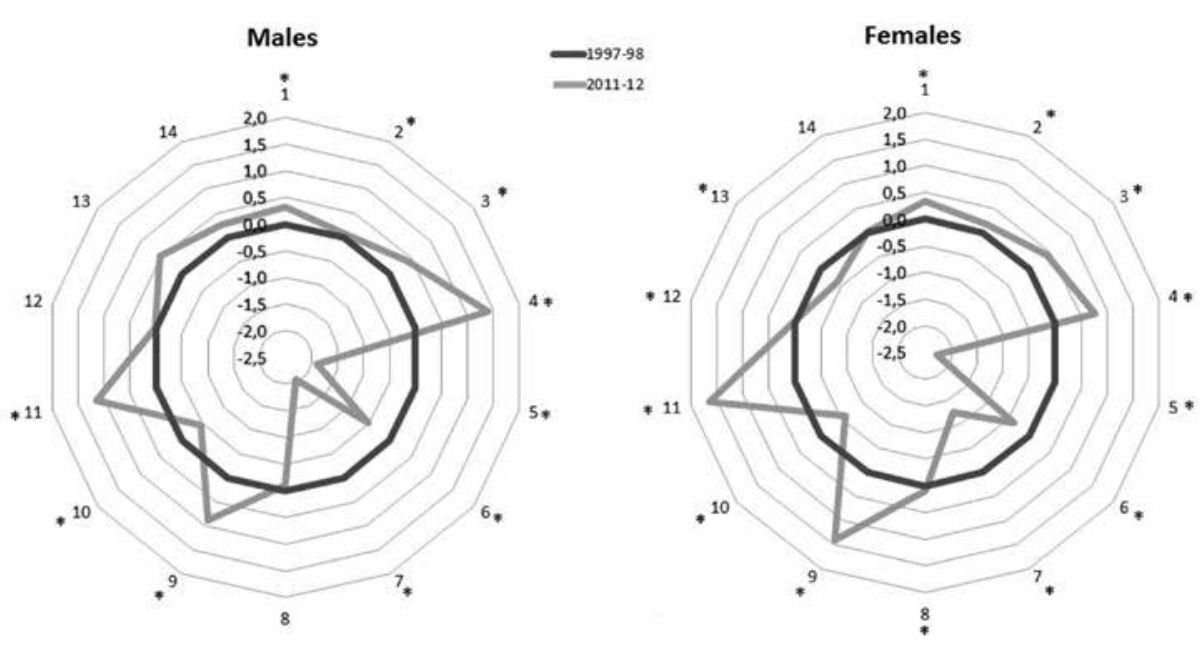

Fig. 1. Standardized differences in physical fitness between the sample in 1997-1998 $(\mathrm{n}=8100)$ and in 2011-2012 ( $\mathrm{n}=432)$ - 1. Body Mass Index; 2. Height; 3. Weight; 4. Body fat percentages; 5. Flamingo test; 6. Plate Tapping test; 7. Sit and Reach test; 8. Standing Broad Jump test; 9. Handgrip Strength test; 10. Sit-up test in 30 seconds; 11. Bent Arm Hanging test; 12. 10×5 m Shuttle Run test; 13. 20 m Shuttle Run test; 14. Maximal oxygen uptake. *Indicates significant differences between the samples (MannWhitney $\mathrm{U}$ test, $\mathrm{p}<0.05$ )

\section{DISCUSSION}

Physical activity is a determinant part of a healthy lifestyle. PA is associated with the decreased risk of cardiovascular diseases, metabolic syndrome, adiposity and obesity, and a variety of physiological and psychological problems [42].

The aim of this study was to examine the physical fitness status of Hungarian university students and to analyze how it had changed in the last 15 years. To our knowledge the health-related physical fitness of university students has not been surveyed in Hungary in a representative sample until 1997 and none was conducted since then either. The health-related physical fitness components have significantly changed between 1997-1998 and 2011-2012. Anthropometric data in the sample of S2 show greater height, weight, BMI values and greater body fat percentages in both males and females than the study fifteen years ago (S1). We did not measure muscle mass, but recently in an other study in Hungary, Konczos and collegues [24] demonstrated that the muscle mass of the studied non-PE college students is under the physiologically optimal level. They found correlation between higher muscle mass and active lifestyle, and also between lower muscle mass and lower aerobic performance. Interestingly enough in our study body composition and aerobic performance seem to correlate but the effect of possibly lower muscle mass is not visible in the results of the handgrip test. The explanation needs further elucidation, but higher body mass might improve short time performances, like hand grip. Since students are more active in their first 
years, we think that our two samples are comparable in terms of age and the physical activity patterns of the general college student populations in both samples. In a sample of American university students $(\mathrm{n}=5100)$ [33] subjects are shorter $(175 \pm 7.5 \mathrm{~cm}$, $162.2 \pm 7.0 \mathrm{~cm})$ but the weight is higher in males $(77.1 \pm 15.8,65.6 \pm 16 \mathrm{~kg})$ and the ratio of body fat mass $(11.6 \pm 6.5,22.4 \pm 6.7 \%)$ is lower in both sexes compared to our data. It is important to note that this studied population had regular physical activity sessions as well. Pribis et al. [33] also noted that there is a significant regression of aerobic capacity between 1996 and 2008 of males and females as well, while physical activity also decreased and body fat percentage increased. Authors found a linear correlation between fat percentage and performance.

The standardized differences in percentages between anthropometric data and Eurofit-test results in this study and the MEFS study is shown in radar charts (Fig. 1). Both sexes show better performance in handgrip tests $(16 \%$ and $28.6 \%$ performance improvement of men and women, respectively) and bent arm hanging tests $(20.9 \%$ and $33.8 \%$ ) than it was observed in the previous generation, while greater explosive leg strength of females was observed (Table 1).

Bad news is that in all other motor tests the student's performance got worse in the last fifteen years, to greater extent in flexibility and balance test. The range of hip joint movement, spinal flexibility and the hamstrings extensibility are $8.76 \mathrm{~cm}$ less in women (30.4\% performance deterioration) and $10.28 \mathrm{~cm}$ in men (38.9\%) than before (Fig. 1), just like in a nationally representative comparison in Canada $(n=3102)$ [39]. The difference between 1997 and 2009 sample is not as great as in our Hungarian sample but the average values are still much higher $(25 \pm 10 \mathrm{~cm}$ of males and $31 \pm 9$ $\mathrm{cm}$ of females). As a consequence of flexibility changes, certain musculoskeletal degenerative diseases might occur earlier in lifetime than in the previous generations. The number of errors in the balance test are also $36.4 \%$ and $52.4 \%$ more in males and females, respectively. The aerobic capacity of males hardly changed compared to the previous Hungarian sample (1997-98), but a decreasing trend is observed among females. In a Hungarian study of Kiss et al. [23] PE students' maximal oxygen uptake $(n=471)$ is higher than in our study because of the regular daily physical activity $(50.3 \pm 5.2 \mathrm{ml} / \mathrm{kg} / \mathrm{min})$, while non-PE university student's performance is only $28.47 \pm 4.8 \mathrm{ml} / \mathrm{kg} / \mathrm{min}(\mathrm{n}=130)$ [39]. Due to the declined cardiorespiratory fitness, the number of cardiovascular and respiratory diseases are expected to be higher in the next decades in Hungary [28]. Physical inactivity/cardiorespiratory fitness is one of the major cardiovascular risk factors (43-61\% of attributable disease burden) between 15 and 59 years of age [34].

Nowadays physical inactivity and sedentary behavior are pervasive public health challenges to overcome. Changes in the Hungarian schools concerning PE have not followed the needs in the last fifteen years, the number of PE sessions decreased in $86 \%$ of the public schools from 3 to 2 or 1.5 [18]. Leyk et al. [29] showed in a German sample that physical performance is the best around pubertal agegroups and physical performance declines fast already in early adulthood in a sedentary lifestyle. With inactive lifestyle the performance of 20-25 years olds might settle back to that of the 10-15 year olds. Performance deterioration was also higher of overweight or obese subjects [29]. 
In our sample overweight also increased in the last decade. Bíró and collegues [5] reported that in a sample of public health students $(\mathrm{N}=194,83.5 \%$ female) $65 \%$ of them exercised once a week, $28 \%$ reported daily exercise. The average BMI of this student population (21.7\%) was very similar to our female population in S2, 13\% was overweight (a little more than in S2) and 2\% obese, less than in our sample.

Karlsson [21] has concluded that PA in childhood has long lasting effects on bone structure, and peak bone mass. Similar conclusion was drawn by Kohrt and collegues [27], other authors [20] reported that PA in childhood reduced the diastolic pressure in adulthood, others reported lower HDL-cholesterol level and lower body fat also [6]. In 2005 a North American expert group concluded that daily at least 1 hour of moderate to vigorous exercise is needed for the proper development in childhood [38], WHO guidelines recommend additional strengthening exercises 3 times weekly. In Hungary in 2004 at the age of 15 years only about $30 \%$ of boys and $20 \%$ of girls were active enough to meet these guidelines [10]. The age group studied at that time is the population entering and being in higher education nowadays. In England self reported physical activity meeting the WHO guidelines of 16-24 years old males increased from $49 \%$ (1997) to $53 \%$ (2008), while of females from $26 \%$ to $35 \%$ [41].

In conclusion it is clear that the backlash of general physical fitness of youth that has grown up already in the new public education system, is the effect of increasing physical inactivity observed in this population. Given that physical fitness of children and youth has a strong effect on their health in their adulthood [6], the observed decline in their PA became a public health threat in Hungary. The question is if the health-related fitness of the Hungarian students had deteriorated in such great extent in fifteen years, what life expectancy the next generation would have at the same age.

\section{ACKNOWLEDGEMENT}

The authors thank Dr. Tamás Szabó providing the data of the study in 1997-1998, contributing to the succes of proper data analyzes.

\section{REFERENCES}

1. Andersen, L. B., Harro, M., Sardinha, L. B., Froberg, K., Ekelund, U., Brage, S., Anderssen, S. (2006) Physical activity and clustered cardiovascular risk in children: a cross-sectional study (The European Youth Heart Study). Lancet 368, 299-304.

2. Antal, M., Nagy, K., Bíró, L., Greiner, E., Regöly-Mérei, A., Domonkos, A., Balajti, A., Szabó, C., Mozsárí, E. (2003) Cross-sectional survey on the nutritional and life-style habits of secondary school students in Hungary. Hung. Med. J. 144, 1631-1636.

3. Balkau, B., Deanfield, J. E., Després, J. P., Bassand, J. P., Fox, K. A., Smith, S.C., Barter, P., Tan, C. E., Van Gaal, L., Wittchen, H. U., Massien, C., Haffner, S. M. (2007) International Day for Evaluation of Abdominal Obesity (IDEA): a study of waist circumference, cardiovascular disease, and diabetes mellitus in 168.000 primary care patients in 63 countries. Circulation 116, 1942-1951.

4. Barabas, A., Fabian, Gy., Ozsvath, K. (1992) Motor fitness investigation in Hungary by Eurofit tests International Council for Physical Fitness Research (ICPER). Symposium 92, Leuven 10-13. Abstracts 37. 
5. Bíró, É., Ádány, R., Kósa, K. (2011) Mental health and behaviour of students of public health and their correlation with social support: a cross-sectional study. BMC Public Health 11, 871-879.

6. Boreham, C., Twisk, J., Neville, C., Savage, M., Murray, L., Gallagher, A. (2002) Association between physical fitness and activity patterns during adolescence and cardiovascular risk factors in young adulthood: the Northern Ireland Young Hearts Project. Int. J. Sports Med. 23, S22-S26.

7. Brodersen, N. H., Steptoe, A., Boniface, D. R., Wardle, J. (2007) Trends in physical activity and sedentary behaviour in adolescence: ethnic and socio-economic differences. Br. J. Sports Med. 41, $140-144$.

8. Brownson, C. R., Boehmer, K. T., Luke, D. A. (2005) Declining rates of physical activity in the United States: What are the contributors? Annu. Rev. Public Health 26, 421-443.

9. Bucsy, G., Katona, Gy. (2002) Motor level, physical fitness research of female college students. Hung. Rev. Sport Sci. 1, 8-11.

10. Currie, C., Roberts, C., Morgan, A., Smith, R., Settertobulte, W., Samdal, O., Barnekow, R. V. (2004) Young people's health in context. Health Behaviour on School-aged Children (HBSC) study: international report from the 2001/2002 survey. World Health Organisation, Copenhagen.

11. Debar, L. L., Schneider, M., Drews, K. L., Ford, E. G., Stadler, D. D., Moe, E. L., White, M., Hernandez, A. E., Solomon, S., Jessup, A., Venditti, E. M., HEALTHY study group (2011) Student public commitment in a school-based diabetes prevention project: impact on physical health and health behavior. BMC Public Health 11, 711.

12. Durnin, J. V., Womersley, J. (1974) Body fat assessed from total body density and its estimation from skin fold thickness measurements on 481 men and women aged from 17-72 years. Br. J. Nutr. 32, 77-97.

13. Eurobarometer. Sport and physical activity. 2010. http://ec.europa.eu/ public_opinion/archives/ebs/ ebs_334_en.pdf

14. EUROFIT European Tests of Physical Fitness, 2nd ed. (1993) Council of Europe, Committee for Development of Sport. Sport Division Strasbourg, Council of Europe Publishing and Documentation Service: Strasbourg

15. Frenkl, R. (1997) Testösszetétel, fittségi állapot (Body composition, physical fitness). In: Som, F. (ed.) Felsőoktatás, Értelmiség, Egészség. Budapest, pp. 17-50.

16. Gyenis, G. (1997) Continuing positive growth changes in height and weight of Hungarian university students. Ann. Hum. Biol. 24, 475-479.

17. Hallal, P. C., Victora, C. G., Azevedo, M. R., Wells, J. C. K. (2006) Adolescent physical activity and health. Sports Med. 36, 1019-1030.

18. Hamar, P., Peters, D. M., Van Berlo, K., Hardman, K. (2006) Physical education and sport in Hungarian schools after the political transition of the 1990s. Kinesiology 38, 86-93.

19. Heimer, S., Misigoj-Durakovic, M., Ruzic, L., Matkovic, B., Prskalo, I., Beri, S., Tonkovic-Lojovic, M. (2004) Fitness level of adult economically active population in the Republic of Croatia estimated by Eurofit system. Coll. Antropol. 28, 223-233.

20. Hernelahti, M., Levalahti, E., Simonen, R. L., Kaprio, J., Kujala, U. M., Uusitalo-Koskinen, A. L., Battié, M. C., Videman, T. (2004) Relative roles of heredity and physical activity in adolescence and adulthood on blood pressure. J. Appl. Physiol. 97, 1046-1052.

21. Karlsson, M. K. (2004) Physical activity, skeletal health and fractures in a long term perspective. J. Musculoskelet. Neuronal Interact. 4, 12-21.

22. Kiss, K., Mavroudes, M., Faludi, J. (2009) Body fat and endurance in female medical university students. Hung. Rev. Sport Sci. 1, 3-6.

23. Kiss, K., Mészáros, Z., Mavroudes, M., Szmodis, M. B., Zsidegh, M., Ng, N., Mészáros, J. (2009) Fitness and nutritional status of female medical university students. Acta Physiol. Hung. 96, 469-474.

24. Konczos, Cs., Bognár, J., Szakály, Zs., Barthalos, I., Simon, I., Oláh, Zs. (2012) Health awareness, motor performance and physical activity of female university students. Biomed. Hum. Kinetics 4, $12-17$. 
25. Kovács, E., Keresztesi, K., Gombocz, J., András-Teleki, J., Kovács, I. (2002) The role of physical education in higher education and possibilities for its development. Kalokagathia 40, 114-121.

26. Kruk, J. (2007) Physical activity in the prevention of the most frequent chronic diseases: an analysis of the recent evidence. Asian Pac. J. Cancer Prev. 8, 325-338.

27. Kohrt, W. M., Bloomfield, S. A., Little, K. D., Nelson, M. E., Yingling, V. R. (2004) American College of Sports Medicine Position Stand: physical activity and bone health. Med. Sci. Sports Exer. 36, 1985-1996.

28. Lee, D. C., Artero, E. G., Sui, X., Blair, S. N. (2010) Mortality trends in the general population: the importance of cardiorespiratory fitness. J. Psychopharmacol. 24, 27-35.

29. Leyk, D., Rüther, T., Witzki, A., Sievert, A., Moedl, A., Blettner, M, Hackfort, D., Löllgen, H. (2012) Physical fitness, weight, smoking, and exercise patterns in young adults. Dtsch. Arztebl. Int. 109, 737-745.

30. Mahar, M. T., Guerieri, M. A., Hanna, S. M., Kemble, D. (2011) Estimation of aerobic fitness from 20-m multistage shuttle run test performance. Am. J. Prev. Med. 4(S), S117-S123.

31. OLEF (2003) Health Survey National Population in 2003. The Gallup Organization.

32. Peolsson, A., Hedlund, R., Oberg, B. (2001) Intra- and inter-testerreliability and reference values for hand strength. J. Rehab. Med. 33, 36-41.

33. Pribis, P., Burtnack, C. A., McKenzie, S. O., Thayer, J. (2010) Trends in body fat, Body Mass Index and physical fitness among male and female college students. Nutrients 2, 1075-1085.

34. Rodgers, A., Ezzati, M., Hoorn, S. V., Lopez, A. D., Lin, R. B., Murray, C. J., Comparative Risk Assessment Collaborating Group (2004) Distribution of major health risks: findings from the Global Burden of Disease study. PLoS Medicine 1, e27.

35. Saar, M. (2008) The relationships between anthropometry, physical activity and motor ability in 10-17-year-olds. PhD thesis, University of Tartu.

36. Sacheck, J. M., Kuder, J. F., Economos, C. D. (2010) Physical fitness, adiposity and metabolic risk factors in young college students. Med. Sci. Sport Exer. 42, 1039-1044.

37. Shields, M., Tremblay, M. S., Laviolette, M., Craig, L. C., Janssen, I., Gorber, C. S. (2010) Fitness of Canadian adults: Results from the 2007-2009 Canadian Health Measures Survey. Health Reports 21, $1-15$.

38. Strong, W. B., Malina, R. M., Blimkie, C. J., Daniels, S. R., Dishman, R. K., Gutin, B., Hergenroeder, A. C., Must, A., Nixon, P. A., Pivarnik, J. M., Rowland, T., Trost, S., Trudeau, F. (2005) Evidence based physical activity for school-age youth. J. Pediatr. 146, 732-737.

39. Szakály, Zs. (2002) Physique, body composition and motor performances in college students. Hung. Rev. Sport Sci. 3-4, 24-29.

40. Tomkinson, G. R., Leger, L. A., Olds, T. S., Cazoria, G. (2003) Secular trends in the performance of children and adolescents (1980-2000). Sports Med. 33, 285-300.

41. Townsend, N., Bhatnagar, P., Wickramasinghe, K., Scarborough, P., Foster, C., Rayner, M. (2012) Physical Activity Statistics 2012. British Heart Foundation, London.

42. Tremblay, S. M., LeBlanc, G. A., Kho, E. M., Saunders, T. J., LArouche, R., Colley, R. C., Goldfield, G., Connor Gorber, S. (2011) Systematic review of sedentary behaviour and health indicators in school-aged children and youth. Int. J. Behav. Nutr. Phys. Act. 8, 98.

43. Tremblay, M. S., Shields, M., Laviolette, M., Craig, C. L., Janssen, I. (2010) Fitness of Canadian children and youth: Results from the 2007-2009 Canadian Health Measures Survey. Statistics Canada. Health Reports 21, 1-14.

44. Tsigilis, N., Douda, H., Tomakidis, S. (2002) Test-retest reliability of the Eurofit test battery administered to university students. Percept. Mot. Skills 95, 1295-1300.

45. Wei, M., Kampert, J. B., Barlow, C. E., Nicheman, M. Z., Gibbons, L. W., Paffenberger, R. S. Jr. Blair, S. N., Brodney, S. (1999) Relationship between low cardiorespiratory fitness and mortality in normal-weight, overweight and obese man. JAMA 282, 1547-1553.

46. World Health Organization (2000) Obesity: Preventing and Managing the Global Epidemic. Report of a WHO Consultation. WHO Technical Report Series 894. Geneva. 